\title{
Avaliação da Qualidade do Transporte Público no Acesso a Unidades de Saúde de Curitiba
}

\author{
Clauciane D. Lima ${ }^{1}$, Altieris M. Peixoto ${ }^{1}$, \\ Luiz Gomes-Jr ${ }^{1}$, Ricardo Lüders ${ }^{1}$, Keiko V. O. Fonseca ${ }^{1}$ \\ ${ }^{1}$ CPGEI / PPGCA / DAINF - Universidade Tecnológica Federal do Paraná (UTFPR) \\ Av. Sete de Setembro 3165 - 80.230-901 - Curitiba - PR - Brazil
}

\begin{abstract}
This work evaluates the quality of public transport provided to users of basic health units of Curitiba city. Two databases have been used: one for health attendances, and another for public transport data. Part of the transport data is coded into a geographic graph database which allows to represent the transport network as well as to compute distances between points of interest. The quality of transport is evaluated by Acessibility and frequency of buses at near bus stops. Acessibility is measured by the walking distance from the stopping point to the nearest Health Unit, considering distances from 100, 300 to $500 \mathrm{~m}$. The results show that $97 \%$ of units have good accessibility, but few bus lines serve more than five US directly.
\end{abstract}

Resumo. Este trabalho avalia a qualidade do transporte público oferecido aos usuários de unidades básicas de saúde (US) da cidade de Curitiba. Para tanto, são utilizadas duas bases de dados abertas: uma contendo os atendimentos das US e outra com os dados do transporte público. Parte dos dados do transporte é representada em uma base de dados de grafos georefenciada que permite representar a topologia da rede de transporte e associar distâncias aos pontos de interesse. A qualidade do transporte é avaliada segundo a Acessibilidade e a frequência dos ônibus nas paradas próximas às US. A acessibilidade é mensurada pela distância de caminhada do ponto de parada à Unidade de Saúde mais próxima, para isso usou-se distâncias de até 100, 300 e $500 \mathrm{~m}$. Os resultados mostram que $97 \%$ das US têm boa acessibilidade, mas poucas linhas de ônibus atendem mais do que cinco US diretamente.

\section{Introdução}

Nas últimas décadas, as cidades brasileiras têm apresentado um crescimento elevado, impactando no sistema de transporte. Esse crescimento gera um aumento em distâncias que não podem ser percorridas a pé ou de bicicleta e dessa forma a dependência do transporte motorizado é inevitável, exigindo um planejamento da oferta e operação dos meios de transporte, principalmente os relacionados ao transporte público [Vasconcellos 1995].

O crescimento da população que mora em áreas urbanas faz com que as cidades enfrentem problemas para fornecer um transporte público de qualidade, surgindo problemas de congestionamentos, acidentes de trânsito, impactos ambientais e perda da qualidade de vida. Segundo [Ferraz and Torres 2004], o equacionamento adequado do transporte urbano é hoje uma preocupação de todos os países, pois a maioria da população mora nas cidades. 
Desde a década de 70, Curitiba tem procurado por inovação buscando investir em obras que priorizem a mobilidade por meio do transporte público, implantando canaletas exclusivas que estão sendo complementadas por faixas exclusivas de ônibus. Além das vias segregadas, o serviço de transporte também evoluiu com a implantação de diferentes categorias de linhas que interagem com os corredores conectando diversas regiões da cidade, que é conhecida como RIT- Rede Integrada de Transporte, onde os usuários podem efetuar a troca de coletivo no interior de terminais sem a necessidade de pagar uma nova tarifa.

De acordo com [Gomide 2003], a existência de um serviço de transporte coletivo eficiente, com custo acessível e de qualidade, que proporcione acessibilidade da população a todo o espaço urbano, pode aumentar consideravelmente a disponibilidade de renda e tempo dos mais pobres, propiciando ainda o acesso aos serviços sociais básicos. A operação do transporte público é planejada para fornecer ao usuário uma determinada qualidade de serviço. Esta qualidade é inferida a partir de dados levantados junto à população, tais como rotas preferenciais, número de passageiros a serem transportados e horários de maior demanda. Com base nestas informações, linhas de ônibus são definidas, assim como sua programação horária. Assim, a qualidade do transporte coletivo é um conceito amplo que pode ser aferida por meio de diversos indicadores de qualidade. Este trabalho avalia a qualidade do transporte em relação à acessibilidade. O conceito de acessibilidade segundo [Ferraz and Torres 2004] está associada a facilidade do usuário chegar ao local de embarque no transporte coletivo e de sair do local de embarque até o destino final da viagem. De acordo com [Vasconcellos 2000], acessibilidade é a medida mais positiva dos efeitos de um sistema de transporte, podendo ser entendida como a facilidade de atingir os destinos almejados. Dessa maneira a acessibilidade pode ser avaliada por parâmetros como o tempo de espera nas paradas, frequência das linhas, distância a ser percorrida, entre outros.

O objetivo deste trabalho é avaliar a qualidade do transporte coletivo por meio da acessibilidade propiciada às unidades de saúde pública de Curitiba, segundo critérios de distância e frequência dos ônibus das paradas mais próximas das unidades. Com isso, espera-se contribuir para a identificação de áreas cujo atendimento possa ser melhorado, elevando a qualidade de atendimento da população.

Este artigo está organizado da seguinte forma. A Seção 2 apresenta conceitos básicos e trabalhos relacionados, a seção 3 apresenta a metodologia utilizada e descreve as bases de dados consideradas. A Seção 4 apresenta os resultados obtidos e a Seção 5 as conclusões e trabalhos futuros.

\section{Conceitos Básicos}

Para [Vasconcellos 1995] a acessibilidade é vista como a habilidade do índividuo se movimentar, locomover e atingir o destino desejado, ou seja, representa a capacidade de movimentação do indivíduo levando em consideração as condições físicas e econômicas da pessoa.

Segundo [Raia 2000], a acessibilidade está relacionada com a oportunidade que o indivíduo possui em realizar uma atividade particular ou uma série de atividades. Está relacionada à mobilidade do indivíduo, localização espacial mais conveniente em relação ao ponto de partida do indivíduo, além das oportunidades de acesso às atividades diversas 
e também na disponibilidade destas atividades. O autor ainda afirma que a acessibilidade é também o potencial disponibilizado pelo sistema de transporte público, de forma a favorecer à todos o desenvolvimento de suas atividades.

De acordo com [Ferraz and Torres 2004], a acessibilidade está associada à facilidade de chegar ao local de embarque do transporte coletivo e de sair do local de desembarque a fim de alcançar o destino final da viagem. Um item que reflete a acessibilidade do sistema de transporte de acordo com [Aguiar 1985] é o número de estações ou pontos de embarque, uma vez que quanto maior for esse número maior será a área coberta pelos serviços de transporte, levando-se em conta que cada ponto possui a sua área de influência própria.

A oportunidade de alcançar um destino é expressa pelo índice de acessibilidade que a relaciona à parâmetros como custo de viagem, tempo de viagem e distância, entre outros.

Para [Pilon and Xavier 2006], a acessibilidade é considerada um dos principais fatores na avaliação da qualidade do transporte público por ônibus. Segundo [Ferraz and Torres 2004], são 12 os principais fatores que influenciam na qualidade do transporte público. Dentre os quais pode-se citar:

- Acessibilidade está associada à facilidade de se chegar ao local de embarque, de deixar o local de desembarque e alcançar o destino final;

- Frequência de atendimento está relacionada ao intervalo de tempo da passagem dos ônibus do transporte público;

A Tabela 1 (adaptado de [Ferraz and Torres 2004]) mostra os atributos que caracterizam a acessibilidade e a frequência do ponto de vista dos usuários, como um serviço de qualidade bom, regular ou ruim.

Tabela 1. Padrões de qualidade para o transporte público de ônibus

\begin{tabular}{lllll}
\hline \multirow{2}{*}{ Fatores } & Parâmetro de & \multicolumn{3}{c}{ Padrões de qualidade } \\
\cline { 3 - 5 } & avaliação & Bom & Regular & Ruim \\
\hline Acessibilidade & $\begin{array}{l}\text { Distância de } \\
\text { caminhada }\end{array}$ & $<300$ & 300 a 500 & $>500$ \\
$\begin{array}{l}\text { Frequência de } \\
\text { atendimento }\end{array}$ & $\begin{array}{l}\text { Intervalo entre } \\
\text { atendimento (min) }\end{array}$ & $<15$ & 15 a 30 & $>30$ \\
\hline
\end{tabular}

\subsection{Acessibilidade e os serviços de saúde}

No caso das unidades de saúde pública da cidade de Curitiba, objeto deste estudo, muitas delas foram projetadas em épocas em que a acessibilidade não era tão relevante quanto hoje. Como o conceito de acessibilidade é amplo, nesse tópico abordaremos o conceito de acessibilidade sobre a perspectiva dos serviços de saúde.

[Scatena et al. 2009] realizou um estudo sobre as dificuldades de acesso ao serviços de saúde para o diagnóstico específico da tuberculose. No estudo ele aborda dois fatores principais negativos do acesso aos usuários: deslocamento até à unidade de saúde e, serviço de atendimento falho. 
[Raia and Pereira 2001] propõe uma metodologia que serve de ferramenta de planejamento, a fim de avaliar a eficácia e eficiência dos equipamentos públicos urbanos existentes. Como resultado, os autores obtiveram um diagnóstico sobre a localização espacial, a acessibilidade aos serviços básicos de saúde para os núcleos de saúde localizados na cidade de Bauru/SP.

[Garcia and Raia 2015] realizou um estudo sobre a acessibilidade aos hospitais na cidade de São Carlos. O estudo aborda a acessibilidade considerando três modos de viagem: a pé; automóvel e transporte público (ônibus). Este estudo se baseia em indicadores de tempo para medir a acessibilidade e dados do censo para estimar o rendimento médio de setores censitários, a fim de verificar se a parcela da população que mais necessita do serviço de saúde possui níveis de acessibilidade adequados.

[Ferreira and Raffo 2013] apresentam um estudo baseado em Sistemas de Informação Georeferenciados (GIS) que mostra a acessibilidade dos habitantes rurais da cidade de Registro (SP) aos postos de saúde e hospitais na região. Os autores afirmam que a análise da acessibilidade é de grande importância para a população, pois todos precisam garantir o direito à assistência médica-sanitária e hospitalar.

Assim, diversos autores abordam a acessibilidade do usuário do sistema de saúde às questões geográficas, ou seja, à localização do serviço de saúde. De forma similar, este trabalho avalia aspectos de posicionamento geográfico das unidades de saúde, mas se concentra no posicionamento das paradas de ônibus próximas, que são o meio de acesso ao transporte público e propiciam a diversidade de oferta de transporte para diferentes origens e destinos da área urbana.

\subsection{Transporte público de Curitiba}

Curitiba é considerada uma referência no transporte público. A cidade conta com a Rede Integrada de Transporte (RIT) desde 1974, onde é possível trocar de linhas em determinados pontos pagando-se uma única tarifa. Atualmente, possui uma frota de 1410 ônibus operantes mais reserva, que procura atender um público de 1.389 .731 passageiros por dia com 251 linhas de ônibus, 329 estações e 21 terminais [URBS 2019]. A administração é realizada pela Urbanização de Curitiba S/A (URBS), empresa de economia mista que fiscaliza as empresas particulares prestadoras de serviços.

Os terminais são pontos de integração localizados em locais estratégicos da cidade que visam atender usuários que moram nas regiões vizinhas que chegam até um dos 21 terminais por meio de "linhas alimentadoras". De dentro dos terminais os usuários do transporte público podem escolher qualquer percurso pagando uma tarifa única, o que ajuda a diminuir o gasto da população com o transporte, permitindo realizar o translado entre linhas nos terminais.

Para [Vasconcellos 2005], os terminais de transporte devem ser confortáveis para os usuários e também devem organizar as chegadas e partidas dos ônibus de forma a minimizar o tempo de transferência dos passageiros. Os ônibus da Linha Expresso têm a função de complementar o trajeto até o centro da cidade por canaletas exclusivas. Curitiba conta ainda com linhas interbairros e linha diretas, que tem a finalidade de conectar outros pontos da cidade. 


\section{Metodologia}

A metodologia utilizada identifica os pontos de ônibus mais próximos de cada unidade de saúde e a frequência de atendimento destes pontos pelas respectivas linhas de ônibus. Para tanto, são utilizadas as bases de dados de atendimentos fornecida pela prefeitura de Curitiba $^{1}$ e as bases de dados do transporte público fornecidas pela URBS. Esta última é utilizada para construir uma base de dados de grafos que contém tanto a topologia da rede de transporte quanto dados georeferenciados de operação.

\subsection{Base de dados das Unidades Básicas de Saúde}

Para este trabalho foi utilizada a base de dados do sistema de saúde de Curitiba "Perfil de atendimento de Enfermagem nas Unidades Municipais de Curitiba ", disponibilizados pela prefeitura de Curitiba $^{2}$, referente aos meses de outubro, novembro e dezembro de 2017.

Após uma filtragem, a base utilizada passou a ter 502.403 linhas e 7 colunas com informações de data do atendimento (dia e hora), data de nascimento, sexo, tipo da unidade (nome da unidade), descrição da unidade (Unidade Básica de Saúde ou Unidade de Pronto Atendimento), meio de transporte, bairro.

Para este trabalho, foram consideradas as informações de data do atendimento, tipo da unidade, descrição da unidade e meio de transporte. Apenas atendimentos das Unidades Básicas de Saúde (US) foram considerados. Quanto aos dados referentes ao meio de transporte uma grande parcela apresentou mais de uma opção por resposta, dessa forma adotou-se "ônibus"para todos os atendimentos que mencionaram este meio de transporte, exceto para as respostas que havia ônibus e carro que contabilizou $50 \%$ para ambos.

\subsection{Base de dados do transporte público}

Através do portal de dados abertos de Curitiba é disponibilizado diariamente em formato JSON, dados sobre a rede de transporte público da cidade. A rede do transporte público de Curitiba foi mapeada em um banco de dados de grafos Neo4 $\mathrm{J}^{3}$ com as informação georeferenciada. Assim, foi possível construir um grafo cujos vértices são as paradas de ônibus e as arestas são as ligações entre paradas definidas pelas rotas das linhas de ônibus em operação. Após, foram inseridos vértices correspondentes a cada uma das 111 unidades de saúde.

Em um banco de dados PostgreSQL foram carregadas as informações das US juntamente com os dados das linhas e horários de ônibus do transporte púlico. Foram utilizados os dados do dia 18 de outubro de 2017 disponibilizados pela URBS ${ }^{4}$ (Urbanização de Curitiba S/A).

No banco de dados Neo4J foi possível identificar as paradas mais próximas de cada US em um raio de até $500 \mathrm{~m}$. Em seguida, foram identidicadas as linhas de ônibus que atendem estas paradas e a respectiva programação horária de cada uma com as informações do banco PostgreSQL.

\footnotetext{
${ }^{1}$ http://www.curitiba.pr.gov.br/dadosabertos/consulta

${ }^{2}$ http://www.curitiba.pr.gov.br/dadosabertos/consulta

${ }^{3}$ https://neo4j.com/

${ }^{4}$ http://dadosabertos.c3sl.ufpr.br/curitibaurbs/
} 


\subsection{Tempo de espera nas paradas}

A metodologia adotada para o cálculo da acessibilidade através do tempo de espera $T$ do transporte para cada US foi proposta por [Garcia and Raia 2015]. Este trabalho apresentou um estudo sobre a acessibilidade de transporte a hospitais realizado na cidade de São Carlos (SP) utilizando a Equação (1),

$$
T=\frac{a}{100} \cdot \frac{\overline{h_{a}}}{2}+\frac{b}{100} \cdot \frac{\overline{h_{b}}}{2}
$$

sendo que $a$ é o percentual de linhas que passam pela US, $\overline{h_{a}}$ é o headway médio (intervalo de tempo entre dois ônibus de uma mesma linha ) de todas as linhas que passam pela US, $b$ é o percentual de linhas que não passam pela US e $\overline{h_{b}}$ é o headway médio de todas as linhas que não passam pela US. Os headways médios $\overline{h_{a}}$ e $\overline{h_{b}}$ são obtidos pela média aritmética dos headways individuais das linhas correspondentes. Estes headways individuais são obtidos pelo número de ônibus programados por hora para percorrer a linha em determinado horário.

\section{Resultados}

\subsection{Distância das paradas e frequência dos ônibus}

Neste trabalho serão analisados os indicadores de acessibilidade relacionados à distância dos pontos de parada mais próximos das US e a frequência das linhas de ônibus nestes pontos. A cidade de Curitiba possui um total de 6500 pontos de parada de ônibus.

Um resultado importante é o número de pontos de ônibus existentes na cidade distantes das US até 100, 300 e 500 metros. De acordo com a Tabela 2, 47\% das US possuem pelo menos um ponto de ônibus distante até $100 \mathrm{~m}$ e $50 \%$ possuem pelo menos um ponto de ônibus distante entre 100 e 300 m das US. Assim, 97\% das US têm acessibilidade boa de acordo com a Tabela 1. Apenas $3 \%$ tem acessibilidade regular, pois estão distantes entre 300 e $500 \mathrm{~m}$ de um ponto de ônibus. Portanto, 100\% das US de Curitiba (111 no total) são atendidas por pelo menos uma parada de ônibus até $500 \mathrm{~m}$ de distância. Ou seja, nenhuma US tem acessibilidade ruim do ponto de vista da distância de um ponto de ônibus. Entretanto, isso é uma aproximação, visto que a distância calculada não é de caminhada, mas entre as coordenadas das US e dos pontos de ônibus.

\section{Tabela 2. Acessibilidade das US segundo a distância $(m)$ da parada mais próxima.}

\begin{tabular}{c|c|c}
\hline Raio $<100$ & $100 \leq$ Raio $\leq 300$ & $300<$ Raio $\leq 500$ \\
\hline $47 \%$ & $50 \%$ & $3 \%$ \\
\hline
\end{tabular}

A Figura 1(a) mostra as US (cruzes) e os respectivos pontos de ônibus (círculos) distantes até $100 \mathrm{~m}$. A Figura 1(b) mostra às opções de linhas disponíveis nos respectivos pontos de ônibus (quanto mais escura a região mais opções de linhas o usuário tem para chegar à US). Similarmente, a Figura 2, mostra as características das paradas distantes até $300 \mathrm{~m}$ e a Figura 3 as paradas distantes até $500 \mathrm{~m}$ das US.

Em até 100 m já é possível encontrar paradas de ônibus, em que todas as opções de linhas já foram detectadas para o usuário chegar até a US. Essas US apresentaram poucas 


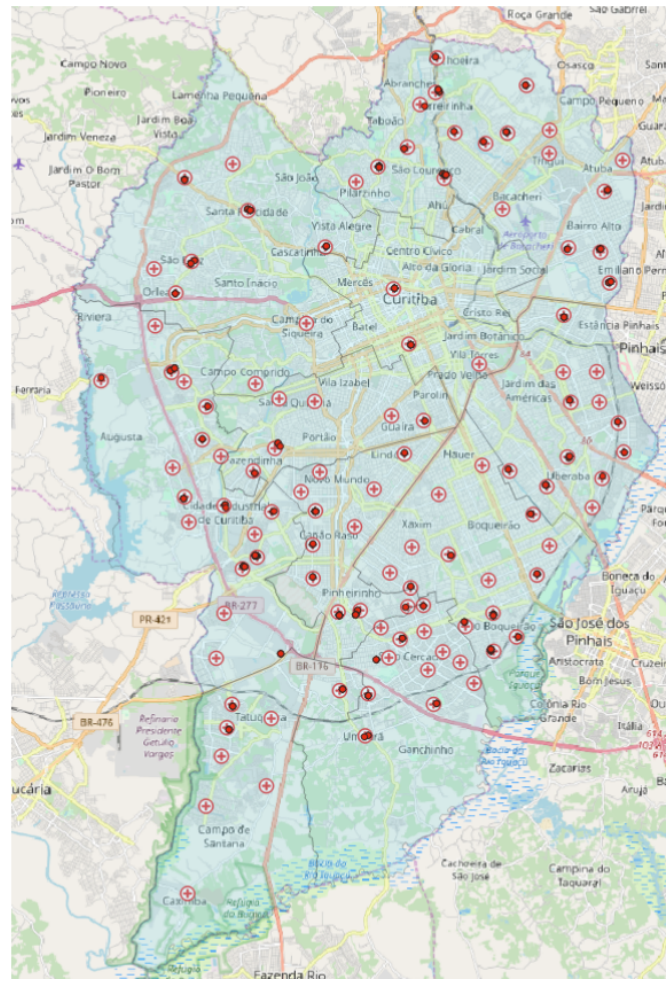

(a) Pontos de ônibus

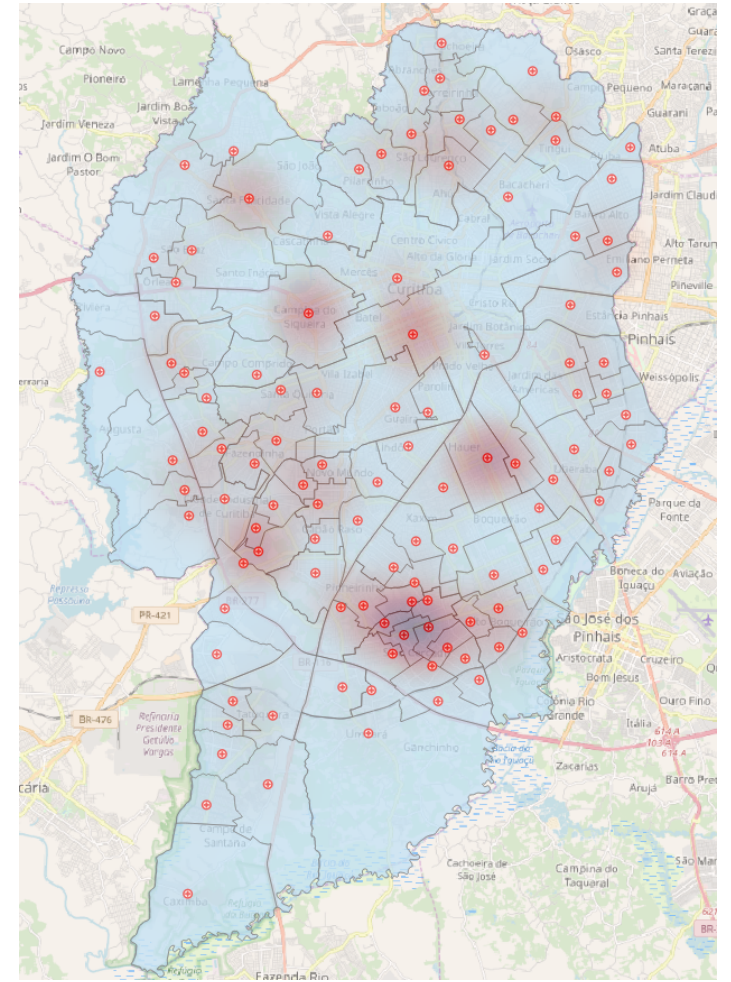

(b) Opções de linhas

Figura 1. Mapa temático das US com paradas de ônibus até $100 \mathrm{~m}$

opções de linhas aos usuários. Os dados foram agregados para análise até $300 \mathrm{~m}, 500 \mathrm{~m}$, mostrando que para algumas US é necessário percorrer distância maiores que $100 \mathrm{~m}$ para obter mais opções de linhas. Até 300 m o número US com $100 \%$ das opções de linhas detectadas cresce de $2,7 \%$ para $24,3 \%$. Porém, a grande maioria das paradas de ônibus ainda possuem opções de linhas para distâncias entre 300 e 500 m .

É possível concluir que existem várias US com poucas opções de linhas, o que pode gerar uma lotação no transporte público, caso o tempo de espera pela linha não seja considerado bom.

O indicador de qualidade da frequência de atendimento está relacionado ao intervalo de tempo entre ônibus, conforme a Tabela 1. Este intervalo de tempo é dado pelo tempo de espera $T$ da Equação (1) em função de $\overline{h_{a}}$ e $\overline{h_{b}}$ para cada US.

Para avaliar este tempo de espera no período das 7:00 às 19:00 foi necessária a descrição das linhas em um raio de $500 \mathrm{~m}$ de cada US, o intervalo de tempo entre ônibus de uma mesma linha e os pontos de paradas. O valor encontrado para $\overline{h_{a}}$ variou de 16 a $60 \mathrm{~min}$ e o valor de $\overline{h_{b}}$ de 33 a $34 \mathrm{~min}$. Considerando $1 \leq a \leq 15$ e $85 \leq b \leq 99$, o tempo médio de espera nas paradas próximas às US variou de 16 a 19 min, ou seja, de qualidade regular segundo a Tabela 1.

A análise referente à qualidade do transporte oferecido pelas linhas distintas que servem às US, foi calculado com base no headway de cada linha. A maioria delas foram classificadas como regulares e ruins, conforme a Tabela 3.

Em seguida, tem-se uma análise da quantidade de US que uma linha de ônibus 


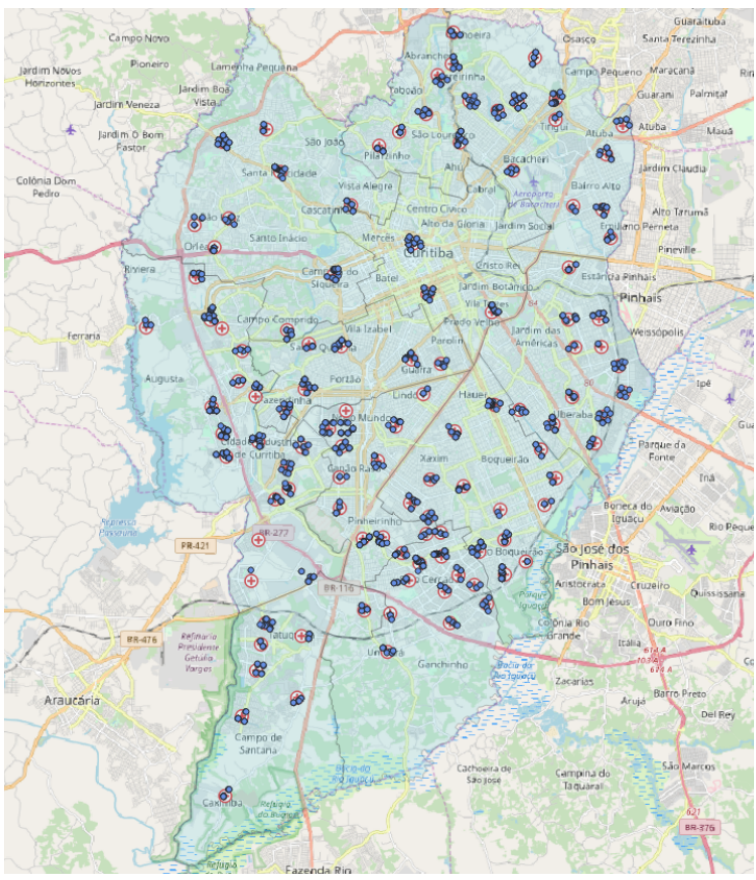

(a) Pontos de ônibus

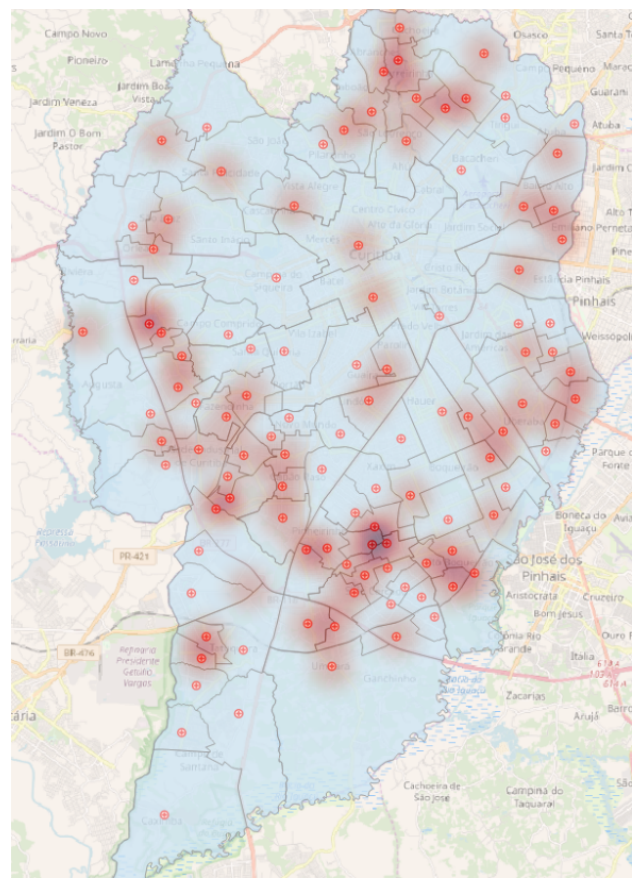

(b) Opções de linhas

Figura 2. Mapa temático das US com paradas de ônibus até $300 \mathrm{~m}$

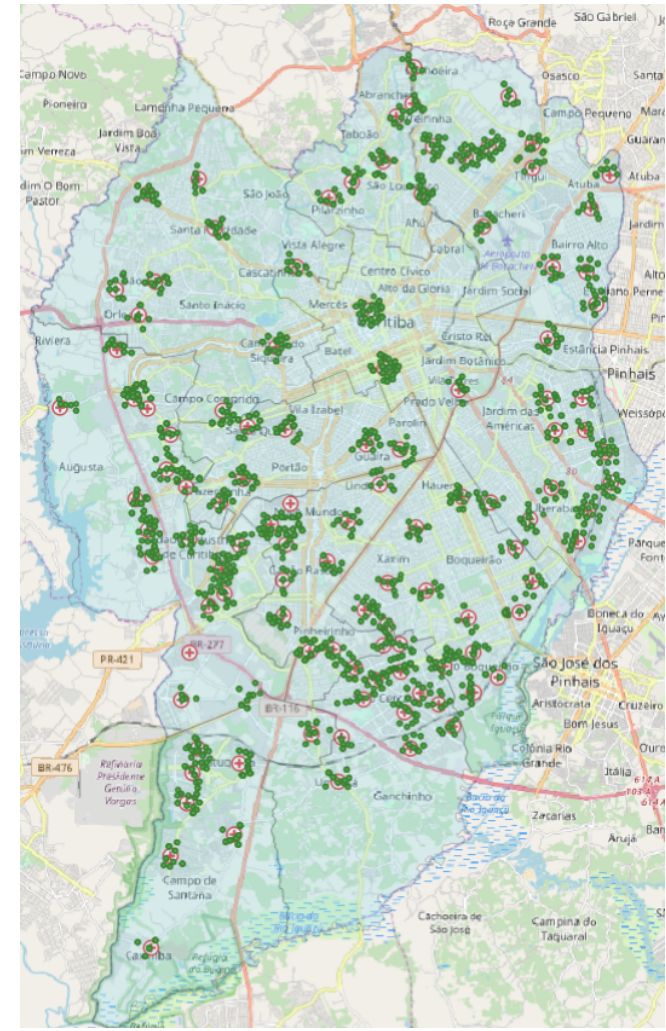

(a) Pontos de ônibus

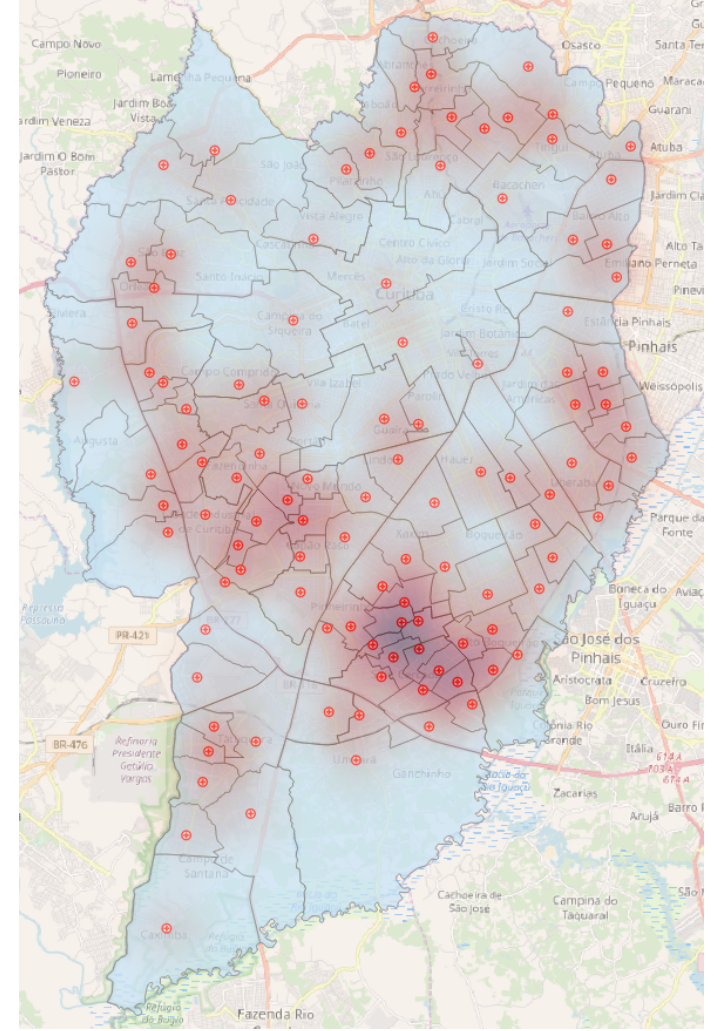

(b) Opções de linhas

Figura 3. Mapa temático das US com paradas de ônibus até $500 \mathrm{~m}$ 
Tabela 3. Qualidade do transporte segundo o tempo de espera.

\begin{tabular}{c|c|c}
\hline Bom & Regular & Ruim \\
\hline $8 \%$ & $49 \%$ & $43 \%$ \\
\hline
\end{tabular}

pode servir. De acordo com a Figura 4, a maioria das linhas de ônibus de Curitiba passam próximas (até $500 \mathrm{~m}$ ) de poucas US. Cerca de $20 \%$ das linhas identificadas passam próximas de uma única US e aproximadamente $30 \%$ passam próximas de duas US. Ou seja, aproximadamente 50\% das linhas de ônibus de Curitiba atendem 1 ou 2 US. Isso é ruim para a população, pois limita a escolha da linha de ônibus para se chegar a uma US, a não ser que o usuário realize translado em um terminal aumentando o tempo de viagem. Mesmo assim, cerca de $15 \%$ das linhas apresentam conexões diretas com 5 ou mais US.

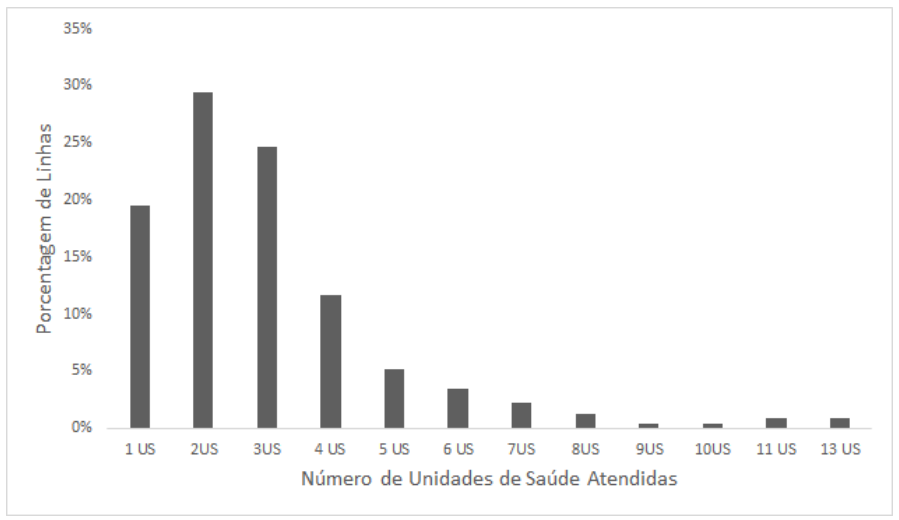

Figura 4. Distribuição das linhas de ônibus de Curitiba em relação ao número de US que atendem

\subsection{Distritos Sanitários}

Curitiba é dividida em dez distritos sanitários que agregam bairros e US. A Tabela 4 mostra a qualidade das linhas que passam próximas (até $500 \mathrm{~m}$ ) das US em relação ao intervalo de atendimento dos ônibus dessas linhas agrupadas por distrito sanitário. A maior parte dos distritos são servidos por linhas consideradas regulares ou ruins, segundo a Tabela 1. Além disso, na rede de transporte é possível encontrar linhas que servem mais do que 4 distritos sanitários. Porém, a maioria serve apenas um distrito como pode ser visto na Tabela 5 .

A partir da base de dados das US, levantou-se o número de atendimentos durante os meses de outubro, novembro e dezembro de 2017, de segunda à sexta-feira, das $7 \mathrm{~h}$ às 19 h. O resultado por distrito sanitário é mostrado na Figura 5, sendo Cajuru o distrito de maior volume de atendimentos registrados no período considerado. Conforme a Tabela 6 , o número de atendimentos por distrito pode ser relacionado à média das distâncias de cada US à parada de ônibus mais próxima (distância mínima). A Tabela 6 mostra que a maior parte dos distritos sanitários possuem US distantes em média $100 \mathrm{~m}$ aproximadamente das paradas mais próximas. Porém, estas distâncias mínimas têm uma variabilidade elevada de acordo com os respectivos desvios padrões. Além disso, os distritos Matriz e Santa Felicidade com os mais baixos números de atendimentos possuem as menores médias de distâncias mínimas (linhas em negrito na Tabela 6). 
Tabela 4. Qualidade das linhas de ônibus por distrito sanitário segundo frequência de atendimento

\begin{tabular}{l|c|c|c}
\hline Distrito sanitário & Bom & Regular & Ruim \\
\hline Boa Vista & $9 \%$ & $36 \%$ & $55 \%$ \\
Cajuru & $14 \%$ & $55 \%$ & $32 \%$ \\
Matriz & $8 \%$ & $53 \%$ & $39 \%$ \\
Boqueirão & $26 \%$ & $56 \%$ & $18 \%$ \\
CIC & $3 \%$ & $66 \%$ & $31 \%$ \\
Portão & $18 \%$ & $58 \%$ & $24 \%$ \\
Santa Felicidade & $21 \%$ & $38 \%$ & $41 \%$ \\
Bairro Novo & $16 \%$ & $56 \%$ & $28 \%$ \\
Pinheirinho & $7 \%$ & $58 \%$ & $35 \%$ \\
Tatuquara & $0 \%$ & $60 \%$ & $40 \%$ \\
\hline
\end{tabular}

Tabela 5. Porcentagem de linhas que servem de 1 até 4 ou mais distritos

\begin{tabular}{c|c}
\hline$\%$ Linhas & Número de distritos \\
\hline $53 \%$ & 1 \\
$34 \%$ & 2 \\
$9 \%$ & 3 \\
$3 \%$ & 4 \\
$1 \%$ & $>4$ \\
\hline
\end{tabular}

\section{Conclusão}

Este artigo apresentou uma avaliação da qualidade da acessibilidade às unidades de saúde públicas da cidade de Curitiba usando o transporte público de ônibus. A qualidade foi mensurada segundo critérios de acessibilidade das paradas dos ônibus às US e frequência de circulação dos ônibus nestas paradas. O número de atendimentos em cada US também foi considerado. Para tanto, foram necessários dados tanto dos atendimentos nas US quanto do sistema de transporte, representado em uma base de grafos georefenciada. Em relação à distância dos pontos de parada até a unidade de saúde, a acessibilidade de $97 \%$ das US foi considerada boa, com pontos localizados a uma distância (euclidiana) menor ou igual a $300 \mathrm{~m}$. Já a avaliação do tempo de espera, mostrou acessibilidade regular das US, para um tempo médio de espera entre 16 a 19 min calculado para cada US. Entretanto, este tempo de espera é uma média que considera a oferta de transporte nos pontos de parada de maneira geral. Caso o usuário necessite de uma linha específica, o tempo de espera pode variar bastante dependendo da linha. Por isso, se fez necessário avaliar a qualidade das linhas individuais nas paradas próximas às US. Como resultado, a maioria delas foi considerada regular ou ruim em relação ao tempo de espera. Em relação à disponibilidade de linhas para acesso às US, os resultados mostram que aproximadamente $50 \%$ das linhas de ônibus de Curitiba servem uma ou duas US. Isso é uma limitação relevante nas opções de linhas de ônibus para acesso às US. Em uma análise por distrito sanitário, as linhas de ônibus também foram avaliadas como regulares ou ruins, atendendo em sua maioria apenas um único distrito. Além disso, os distritos com menor número de atendimentos possuem US com menor distância em média das paradas mais próximas. Isso 


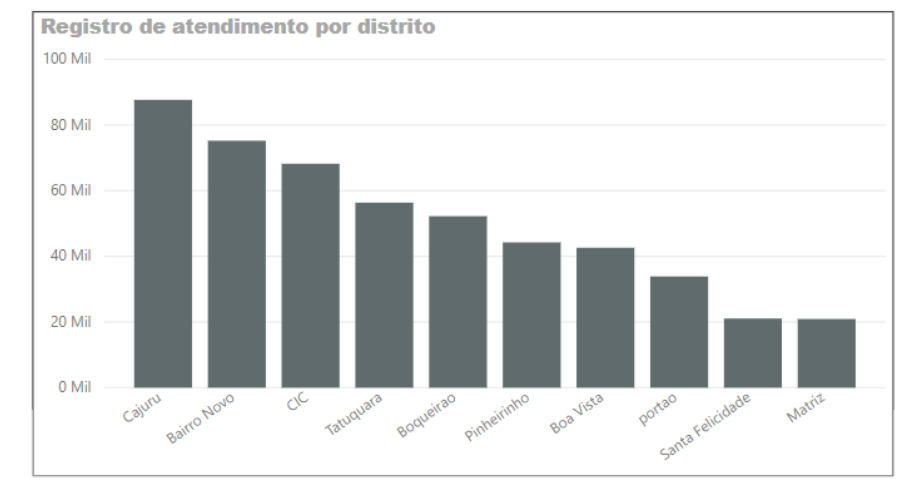

Figura 5. Número de atendimentos nas US por distrito sanitário

Tabela 6. Relação entre a média das distâncias (mínima) de cada US à parada de ônibus mais próxima e o número de atendimentos por distrito sanitátio

\begin{tabular}{l|c|c|c}
\hline Distrito sanitário & Média das distâncias mínimas & Desvio padrão & No. atendimentos \\
\hline Boa Vista & 105,3 & 58,3 & 42623 \\
Cajuru & 136,7 & 75,7 & 87673 \\
Matriz & $\mathbf{6 3 , 3}$ & 45,1 & $\mathbf{2 0 9 1 0}$ \\
Boqueirão & 102,1 & 55,1 & 52233 \\
CIC & 101,2 & 87,0 & 68207 \\
Portão & 115,0 & 15,2 & 33874 \\
Santa Felicidade & $\mathbf{9 5 , 6}$ & 63,5 & $\mathbf{2 1 0 6 9}$ \\
Bairro Novo & 108,3 & 43,4 & 75218 \\
Pinheirinho & 112,7 & 91,2 & 44244 \\
Tatuquara & 136,3 & 69,7 & 56352 \\
\hline
\end{tabular}

pode significar que distritos com menor população são melhor atendidos pelo transporte público. Porém, outras análises são necessárias para verificar, por exemplo, se estes distritos apresentam populações concentradas em determinadas áreas. Como trabalho futuro, pretende-se considerar indicadores para tempo de viagem necessário para se deslocar até uma US e áreas de abrangência das US. A área de abrangência de uma US é aquela que pode ser atingida por uma linha de ônibus que possui uma parada próxima da US. Futuramente, pretende-se avaliar também a relação entre a qualidade do transporte público disponibilizado nas US e a situação sócio-econômica das populações que são atendidas.

\section{Referências}

Aguiar, E. M. (1985). Análise crítica dos indicadores de eficiência e eficácia propostos para avaliação de sistemas de transporte público urbano. Tese de doutorado, EESC/USP, São Carlos.

Ferraz, A. C. P. and Torres, I. G. E. (2004). Transporte público urbano. Rima Editora.

Ferreira, R. V. and Raffo, J. G. (2013). Cartography of geographic access to rural health care services of the region of registro. Confins-Revista Franco - Brasileira de Geografia. 
Garcia, P. B. M. and Raia, A. A. (2015). Análise da acessibilidade a hospitais: Estudo de caso para as cidades de são carlos (sp) e rio claro (sp). Revista Brasileira de Gestão Urbana, 7:21-47.

Gomide, A. A. (2003). Transporte urbano e inclusão social: Elementos para políticas públicas. Brasília, IPEA.

Pilon, J. A. and Xavier, A. A. P. (2006). O emprego de microônibus na melhoria da acessibilidade ao sistema municipal de transporte coletivo da cidade de vitória-es. $X X V I$ ENEGEP - Fortaleza, CE.

Raia, A. A. and Pereira, C. A. (2001). Metodologia para simulação de mapas de equidade e acessibilidade a equipamentos e acessibilidade a equipamentos públicos urbanos. Relátorio de pesquisa São Carlos.

Raia, A. A. J. (2000). Acessibilidade e mobilidade na estimativa de um índice de potencial de viagens utilizando redes neurais artificiais e sistemas de informação geográfica. Tese (Doutorado em Engenharia Civil)- Departamento de Transportes, USP/EESC, São Carlos.

Scatena, L. M., Villa, T. C. S., Netto, A. R., Kritski, A. L., Figueiredo, T. M. R. M., Vendramini, S. H. F., Assis, M. M. A., and Motta, M. C. S. (2009). Difficulties in the accessibility to health services for tuberculosis diagnoses in brazilian municipalities. Rev Saúde Pública.

URBS (2019). Urbs em números https://www.urbs.curitiba.pr.gov . br/transporte/rede-integrada-de-transporte. Online; acesso em 09/03/2019.

Vasconcellos, E. A. (1995). A crise do planejamento de transportes nos paises em desenvolvimento:reavaliando pressupostos e alternativas, volume 3, pages 7-26.

Vasconcellos, E. A. (2000). Transporte urbano nos países em desenvolvimento. Unida Editora, são Paulo.

Vasconcellos, E. A. (2005). A cidade, o transporte e o trânsito. Pro livro, São Paulo. 